\title{
Parada cardiorrespiratória na pandemia por coronavírus: revisão compreensiva da literatura
}

\author{
Cardiorespiratory arrest in a coronavirus pandemic: comprehensive literature review \\ Paro cardiorrespiratorio en una pandemia de coronavirus: revisión exhaustiva de la literatura
}

\author{
Debora Mazioli Machado'; Carla de Azevedo Vianna"; Lucimar Casimiro de Souzall'; \\ Taina Coutinho Leite ${ }^{\prime V}$; Marcelle Miranda da Silva ${ }^{v}$; Juliana Faria Campos ${ }^{V I}$
}

\begin{abstract}
RESUMO
Objetivo: apresentar atualizações para a ressuscitação cardiopulmonar em pacientes suspeitos e confirmados com COVID-19. Método: revisão compreensiva da literatura, com síntese narrativa das evidências de diretrizes e recomendações da Organização Mundial de Saúde, Associação de Medicina Intensiva Brasileira, American Heart Association, Resuscitation Council UK, American College of Surgions Committee on Trauma e National Association of Emergency Medical Technicians. Resultados: as principais atualizações trazem informações sobre especificidades das manobras de ressuscitação cardiopulmonar; preparação do ambiente, recursos humanos e materiais, reconhecimento da parada cardiorrespiratória e ações iniciais; estratégias de ventilação e acesso invasivo da via aérea; ajustes do ventilador mecânico e manobras de ressuscitação cardiopulmonar em pacientes pronados. Considerações finais: profissionais de saúde envolvidos no atendimento à parada cardiorrespiratória de pacientes suspeitos e/ou confirmados com COVID-19 podem encontrar inúmeros desafios, portanto devem seguir com rigor o protocolo estabelecido para maximizar a efetividade das manobras de ressuscitação e minimizar o risco de contágio pelo vírus e sua disseminação. Descritores: Pandemias; Infecções por Coronavírus; Reanimação Cardiopulmonar; Massagem Cardíaca.
\end{abstract}

\section{ABSTRACT}

Objective: to present updates for cardiopulmonary resuscitation in suspected and confirmed patients with COVID-19. Method: comprehensive literature review with narrative synthesis of the evidence of guidelines and recommendations from World Health Organization, Associação de Medicina Intensiva Brasileira, American Heart Association, Resuscitation Council UK, American College of Surgions Committee on Trauma and National Association of Emergency Medical Technicians. Results: the main updates bring information about the specifics of cardiopulmonary resuscitation maneuvers; preparation of the environment and human and material resources, recognition of cardiorespiratory arrest and initial actions; ventilation and invasive airway access strategies; mechanical ventilator adjustments and cardiopulmonary resuscitation maneuvers in patients in the prone position. Final considerations: health professionals involved in the care of cardiorespiratory arrest of suspected and/or confirmed patients with COVID-19 can face numerous challenges, so they must strictly follow the protocol established to maximize the effectiveness of resuscitation maneuvers and minimize the risk of contagion by the virus and its spread.

Descriptors: Pandemics; Coronavirus Infections; Cardiopulmonary Resuscitation; Heart Massage.

\section{RESUMEN}

Objetivo: apresentar actualizaciones para la reanimación cardiopulmonar en pacientes sospechos os y confirmados con COVID-19. Método: revisión exhaustiva de la literatura con síntesis narrativa de la evidencia de guías y recomendaciones de la Organización Mundial de la Salud, Associação de Medicina Intensiva Brasileira, American Heart Association, Resuscitation Council UK, American College of Surgions Committee on Trauma and National Association of Emergency Medical Technicians. Resultados: las principales actualizaciones aportan información sobre los detalles de las maniobras de reanimación cardiopulmonar; preparación del medio ambiente y recursos humanos y materiales, reconocimiento de paro cardiorrespiratorio y acciones iniciales; estrategias de ventilación y acceso invasivo a las vías aéreas; ajustes del ventilador mecánico y maniobras de reanimación cardiopulmonar en pacientes en decúbito prono. Consideraciones finales: los profesionales de la salud involucrados en la atención del paro cardiorrespiratorio de pacientes sospechosos y/o confirmados con COVID-19 pueden enfrentar numerosos desafíos, por lo que deben seguir estrictamente el protocolo establecido para maximizar la efectividad de las maniobras de reanimación y minimizar el riesgo de contagio por el virus y supropagación. Descriptores: Pandemias; Infecciones por Coronavirus; Reanimación Cardiopulmonar; Masaje Cardíaco.

\section{INTRODUÇÃO}

Desde 30 de janeiro de 2020 a disseminação da Corona Virus Disease (COVID-19), doença causada pelo novo coronavírus (Sars-cov-2), constitui uma emergência de saúde pública de importância internacional, tendo sido designada como uma pandemia em março de 2020, pela Organização Mundial da Saúde (OMS) ${ }^{1,2}$. De acordo com relatório atualizado, 5.175 .925 casos de COVID-19 foram confirmados no mundo e 338.089 óbitos, até 23 de maio. Na mesma data o Brasil constatou 347.398 casos e 22.013 mortes $^{2}$.

'Enfermeira. Mestre. Hospital Pró Cardíaco. Rio de Janeiro, Brasil. E-mail: binhamazioli@gmail.com. ORCID: https://orcid.org/0000-0003-4601-8081

"Enfermeira. Aluna do curso de Mestrado, Universidade Federal do Rio de Janeiro e Hospital Pró Cardíaco. Rio de Janeiro, Brasil. E-mail: carlinhaavianna@hotmail.com. ORCID: https://orcid.org/0000-0003-4778-7800

I'Enfermeira. Aluna do curso de Mestrado, Universidade Federal do Rio de Janeiro e Hospital Samaritano. Rio de Janeiro, Brasil. E-mail: lucimarrj@yahoo.com.br. ORCID: https://orcid.org/0000-0003-0709-5877

IVEnfermeira. Aluna do curso de Mestrado, Universidade Federal do Rio de Janeiro e Hospital Pró Cardíaco. Rio de Janeiro, Brasil. E-mail:

tainacoutinholeite@ hotmail.com. ORCID: https://orcid.org/0000-0002-8092-3539

venfermeira. Pós doutora. Professora Associada, Universidade Federal do Rio de Janeiro. Brasil. E-mail: marcellemsufrj@gmail.com. ORCID: https://orcid.org/0000-0003-4872-7252

VIEnfermeira. Doutora. Professora Adjunta, Universidade Federal do Rio de Janeiro. Brasil. E-mail: jujufariacampos@yahoo.com.br. ORCID: https://orcid.org/0000-0001-7254-5251 
Aproximadamente $12 \%$ a $19 \%$ dos pacientes positivos para COVID-19 requerem internação hospitalar ${ }^{3}$. Dez a $15 \%$ dos pacientes infectados correm risco de desenvolver insuficiência respiratória exigindo admissão em unidades de terapia intensiva ${ }^{1,4}$. Dados da Comissão Nacional de Saúde da China demonstraram que em fevereiro de 2020, em Wuhan, cerca de $15 \%$ dos pacientes desenvolveram pneumonia grave e $6 \%$ necessitaram de suporte ventilatório não invasivo ou invasivo ${ }^{5}$.

A American Heart Association e colaboradores corroboram que de $3 \%$ a $6 \%$ dessas vítimas progridem com um quadro grave ${ }^{3}$. Assim torna-se essencial por parte dos assistentes de saúde, em especial a equipe de enfermagem, por sua maior proximidade no processo do cuidado, estabelecer medidas de vigilância e prevenção para monitorar continuamente os sinais precoces de deterioração clínica ${ }^{2,6,7}$.

No contexo de gravidade desta recente infecção, a parada cardiorrespiratória (PCR) torna-se comum em virtude de:insuficiência respiratória hipoxêmica secundária à síndrome do desconforto respiratório agudo (SDRA), lesão miocárdica, arritmias ventriculares, choque, assim como o alargamento do intervalo QT, que é um dos possíveis eventos causados pelo tratamento experimental proposto com as drogas hidroxicloroquina e a azitromicina ${ }^{3}$.

Diante do novo cenário estabelecido, a atualização e a elaboração de protocolos específicos tornam-se necessários neste enfrentamento. Ademais, com o crescimento exponencial das contaminações estima-se que os casos de PCR também aumentem. Nesse sentido, este artigo tem como objetivo reunir as principais atualizações para a ressuscitação cardiopulmonar (RCP) em pacientes suspeitos e confirmados com COVID-19.

\section{MÉTOdo}

Trata-se de revisão compreensiva da literatura realizada no mês de abril de 2020, a partir da síntese narrativa das evidências sobre as principais atualizações para a ressuscitação cardiopulmonar (RCP) em pacientes suspeitos e confirmados com COVID-19 contidas nas principais diretrizes e recomendações oficiais divulgadas pelos órgãos vinculados à área da saúde brasileira e internacional: Organização Mundial de Saúde, Associação de Medicina Intensiva Brasileira, American Heart Association, Resuscitation Council UK, American College of Surgions Committee on Trauma, National Association of Emergency Medical Technicians.

\section{RESULTADOS}

As manobras de RCP devem seguir as recomendações e diretrizes dos órgãos especializados e algumas mudanças relacionadas ao atendimento à PCR nos ambientes hospitalares em pacientes com suspeita ou confirmação de COVID-19 foram reunidas e publicadas. Os resultados encontrados referem-se especialmente a existência de riscos extras aos profissionais de saúde, em virtude da possível exposição a fluidos corporais, administração das compressões torácicas, além de diversos procedimentos que envolvem a geração de aerossóis, como a ventilação com pressão positiva e a instalação de vias aéreas avançadas ${ }^{8}$.

Os profissionais de enfermagem compõem um grupo estratégico para garantir a eficácia e a segurança do atendimento na PCR. Esta equipe, na grande maioria das vezes, é a primeira a identificar e iniciar o atendimento nos ambientes hospitalares, compondo também os profissionais responsáveis pelo provisionamento dos materiais essenciais que darão suporte ao atendimento dos pacientes. Portanto, é de extrema importância que toda equipe de enfermagem esteja alinhada ao fluxo de atendimento à PCR dos pacientes com suspeita ou confirmação de COVID-19.

\section{Redução de exposição de profissionais e uso de EPIs durante a RCP em pacientes suspeitos ou confirmados com COVID-19}

Preocupar-se com a segurança da cena, ou seja, do prestador de saúde, imediatamente antes de iniciar o atendimento à vítima, sempre foi uma recomendação dos principais guidelines de emergência ${ }^{6,9,10}$.Os princípios gerais para RCP em pacientes suspeitos e confirmados com COVID-19 envolvem diversas medidas para reduzir a exposição dos profissionais, incluindo o estabelecimento de equipes exclusivas de atendimento à PCR. Times de Resposta Rápida (TRR) deverão ser considerados diante de deterioração aguda ${ }^{11}$.

Por ser um procedimento com potencial geração de aerossóis, diante dos primeiros sinais de riscos de $P C R^{3}$, deve-se atentar para o transporte rápido e seguro para uma unidade de isolamento respiratório com pressão negativa e filtro HEPA (High Efficiency Particulate Arrestance), filtro de ar particulado de alta eficiência ${ }^{13,12,13}$. Na ausência deste, recomenda-se um quarto privativo e com a porta fechada ${ }^{13}$.

O menor número possível de profissionais deverá atuar no ambiente, normalmente quatro pessoas com funções designadas ${ }^{1}$, uma vez que partículas virais podem permanecer suspensas no ar por cerca de uma hora e serem inaladas pelas pessoas próximas ${ }^{3}$. Neste intuito deve-se, inclusive, ser considerado o uso de dispositivos mecânicos, que substituam as compressões torácicas manuais ${ }^{3,8}$. 
Embora possa ocorrer retardo no início das compressões torácicas, zelar pela segurança da equipe é uma ação primordial. Portanto, os equipamentos de proteção individual (EPI) devem estar disponíveis no carro de ressuscitação para pronto uso por todos os profissionais envolvidos no atendimento ${ }^{11}$. É essencial minimizar a exposição desnecessária, uma vez que, ao se tornarem vulneráveis, reduzem a força de trabalho já sobrecarregada mas principalmente pela apreensão diante da possibilidade de se tornarem gravemente doentes ${ }^{3}$.

As recomendações de EPI podem variar com base nos dados epidemiológicos, na disponibilidade atuais de insumos e rotinas institucionais. Apesar das compressões torácicas e desfibrilação serem consideradas intervenções de ressuscitação de menor risco $^{1}$,a utilização do bolsa-válvula-máscara (BVM) e a intubação endotraqueal tem um potencial aumentado para aerolização $0^{1,3,4}$, portanto a paramentação destes profissionais de acordo com a ANVISA, devem incluir ${ }^{13}$ : higiene das mãos com água e sabonete líquido ou preparação alcoólica a 70\%; óculos de proteção ou protetor facial (face shield); máscara N95/PFF2 ou equivalente (procedimento que gera aerossóis); avental impermeável (procedimento que gera aerossóis); luvas de procedimento e gorro (procedimento que gera aerossóis).

Os macacões com capuz integrado poderão ser utilizados, avaliando-se a facilidade de remoção, no intuito de evitar contaminação durante esta etapa. Não há evidências definitivas de que o respirador purificador de ar motorizado (PAPR) reduza a probabilidade de transmissão viral no cenário de procedimentos com geração de aerossóis, apesar de ter um fator de proteção mais alto em comparação aos respiradores N95. PAPR com capuz cobrindo toda a cabeça e pescoço podem fornecer proteção adicional contra contaminação em comparação com o equipamento típico usado em conjunto com uma máscara N95, tendo como principais obstáculos à implementação: o treinamento para remover com segurança o equipamento sem contaminação, a necessidade de protocolos sobre a higienização dos dispositivos para uso seguinte e a disponibilidade local ${ }^{1}$.

Sabe-se que quanto mais precoce as compressões torácicas e a desfibrilação forem iniciadas maiores são as chances de sucesso da RCP. Esse atendimento precoce pode não ser possível para os pacientes confirmados ou com suspeita de COVID-19, isso porque o tempo gasto para a paramentação pode ser bastante elevado.

Além disso, manter a utilização dos EPIs durante as manobras de RCP pode ser desafiador. Os movimentos gerados pelo socorrista ao comprimir o tórax podem levar ao desposicionamento dos dispositivos de segurança do profissional de saúde. Manter qualquer dispositivo fixado ao rosto no momento da manobra se torna um grande desafio para estes profissionais.

O impacto da paramentação na qualidade da RCP foi questionado em estudo onde foram investigados 136 casos de pacientes que sofreram PCR e que foram submetidos à manobra de ressuscitação. Destes apenas quatro pacientes sobreviveram aos 30 dias a contar da data da parada cardiorrespiratória, o que representou apenas $2,9 \%$ da amostra. A qualidade incerta das manobras de reanimação, que pode variar, por exemplo, a depender do tipo de EPI que o profissional esteja utilizando, por limitar seu movimento para adequada compressão cardíaca, foi considerada um dos fatores chave para reanimação de pacientes com pneumonia grave por COVID-19 em Wuhan ${ }^{14}$.

Ressalta-se que, diferente das rotinas atuais, ao invés de levar o carro de reanimação para o leito, kits específicos deverão ser considerados, pelo desafio relacionado à descontaminação, minimizando assim o desperdício de materiais e medicamentos após o procedimento ${ }^{1}$. Uma outra estratégia consiste em manter um profissional fora do quarto, com a porta fechada, sendo este dedicado a entrega de quaisquer equipamentos/medicamentos adicionais que possam ser exigidos ${ }^{11,15}$. Entretanto, deve-se ter atenção, pois o trânsito recorrente de pessoas para a sala pode aumentar o risco de transmissão viral ${ }^{1}$.

\section{Reconhecimento da PCR e ações iniciais}

As normas de tomada de decisão que envolvem a ressuscitação devem permanecer individualizadas ${ }^{7}$, porém, ainda que os desfechos da PCR nestes pacientes sejam desconhecidos, a mortalidade é alta, agravando-se quando associada a fatores de risco como idade elevada e comorbidades, particularmente as doenças cardiovasculares ${ }^{3}$. Garantir a comunicação efetiva entre os membros da equipe a respeito das ordens de "não ressuscitação cardiopulmonar" (NRCP) estabelecidas junto aos familiares e nos rounds devem ser uma prioridade, assim como a adequada documentação desta definição ${ }^{7}$. Da mesma maneira é fundamental seguir as políticas institucionais relacionadas aos cuidados paliativos e de terminalidade ${ }^{12}$

O reconhecimento da PCR se dará através da ausência de: consciência, pulso carotídeo e respiração normal ${ }^{6,7}$. Ativar o TRR, se disponível na instituição, é uma medida altamente eficaz.

A RCP deve ser iniciada pelas compressões torácicas e o ritmo avaliado rapidamente, para determinação do algoritmo apropriado ${ }^{11}$. Contudo, em vigência de ritmos chocáveis (fibrilação ventricular e taquicardia ventricular sem pulso) e um desfibrilador prontamente disponível, a desfibrilação deverá ocorrer rapidamente, antes mesmo de se 
iniciarem as compressões, uma vez que o restabelecimento da circulação espontânea poderá impedir a necessidade de novas medidas de ressuscitação ${ }^{3,7}$.

Destaca-se que nas paradas cardíacas por COVID-19 80\% apresentam atividade elétrica sem pulsoou assistolia, o que reduz a resposta positiva às manobras, com sobrevivência e alta hospitalar de cerca de 15 a $20 \%{ }^{14,16}$.

\section{Estratégias de ventilação e acesso invasivo da via aérea}

É unânime entre os especialistas que a desfibrilação dos ritmos chocáveis não deve ser adiada para acesso às vias aéreas ou outros procedimentos ${ }^{3,7,12}$. Após esta avaliação e desfibrilação dosritmos chocáveis, deve-se proceder a intubação na primeira oportunidade possível para um melhor padrão de ventilação/oxigenação ${ }^{3}$, uma vez que a hipóxia é uma das principais causas de PCR nestes pacientes ${ }^{12}$.

Como a intubação de pacientes críticos com coronavírus relacionados à SDRA grave foi associada a episódios de contaminação dos profissionais de saúde, o procedimento deve ser priorizado na tentativa de promover o isolamento das vias aéreas e reduzir a aerolização ${ }^{1}$ e ser realizado pela pessoa mais qualificada da equipe, para otimizar o sucesso da primeira tentativa ${ }^{1,3,4,7}$.

As compressões torácicas devem ser interrompidas no momento da intubação e o uso do videolaringoscópio considerado, se disponível, na tentativa de diminuir a exposição do intubador e assistentes às partículas de aerossol ${ }^{3,11,17}$. Utilizar a capnografia com forma de onda é o método de escolha para confirmar o correto posicionamento do tubo endotraqueal ${ }^{3,4}$.

A ventilação manual com BVM ou bolsa-tubo endotraqueal deve ser evitada, pelo elevado risco de aerolização e contaminação da equipe. Em situações de extrema necessidade de ventilação com BVM, a técnica para vedação da máscara deverá envolver dois profissionais, com a utilização de uma cânula orofaríngea ${ }^{12}$.

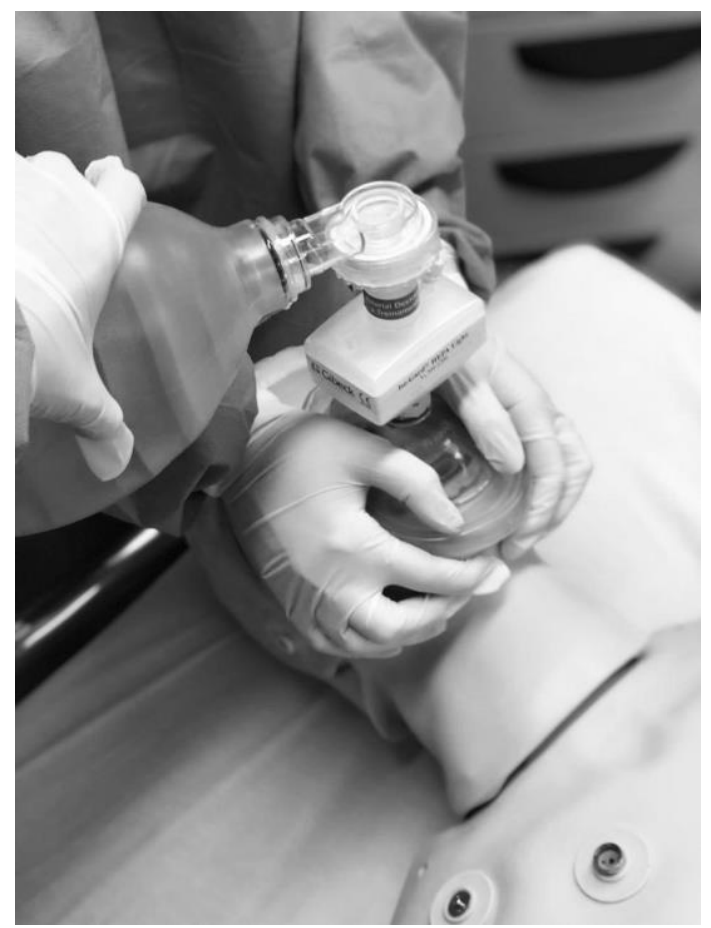

FIGURA 1: Técnica utilizada para ventilação manual com BVM, utilizando dois profissionais de saúde. Fonte: os autores. Rio de Janeiro - RJ, Brasil, 2020.

A fim de otimizar estratégias de oxigenação, reduzindo o risco de contaminação, um filtro HEPA deverá ser acoplado entre a bolsa e a máscara. Do mesmo modo, após a intubação, um filtro HEPA deverá ser posicionado no circuito ventilatório, logo após o tubo traqueal e outro na saída expiratória do ventilador mecânico ${ }^{3,12}$. 


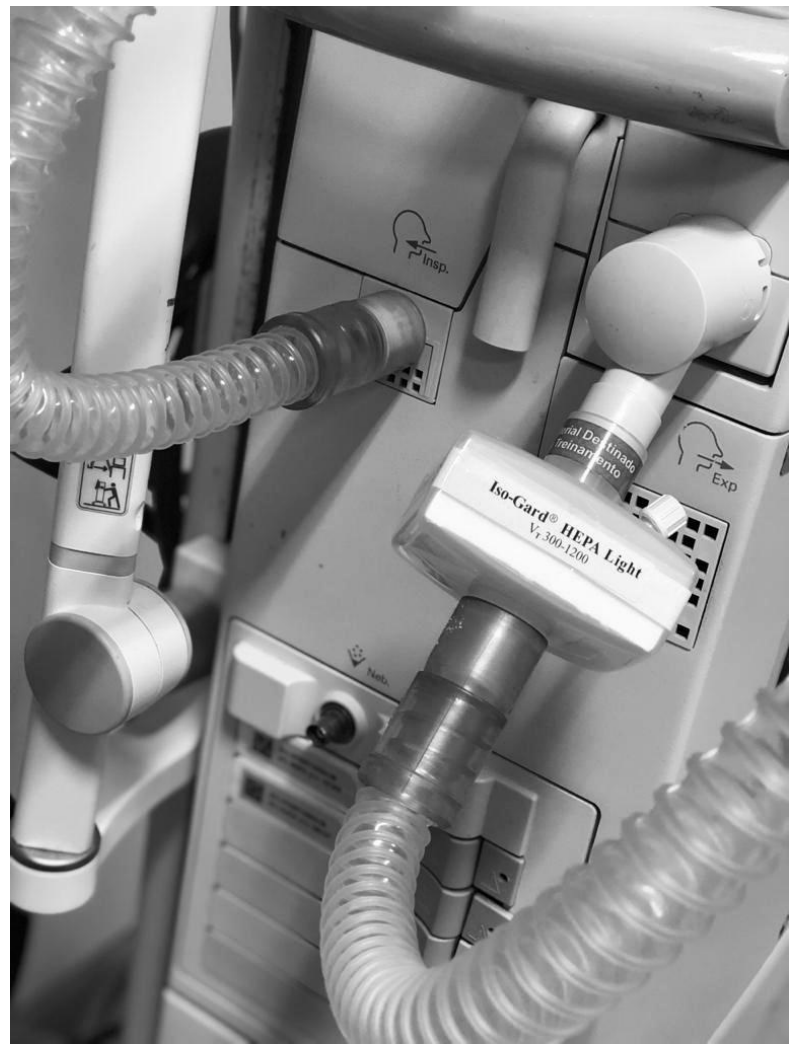

FIGURA 2: Filtro HEPA posicionado na saída expiratória do ventilador mecânico. Fonte: os autores. Rio de Janeiro - RJ, Brasil, 2020.

Caso a intubação atrase, a ventilação com uma via aérea supraglótica ou o BVM com um filtro HEPA deverão ser considerados ${ }^{3}$. Apesar de não haver evidências consistentes demonstrando que o uso de dispositivos supraglóticos gerem menos aerossóis que a BVM, há relatos sobre a facilidade para sua inserção, a possibilidade de atingir pressão de vedação suficiente e de que seu uso pode poupar mão de obra, reduzindo a exposição da equipe. Ademais, dispositivos supraglóticos de nova geração fornecem um conduíte para realização da intubação traqueal ${ }^{18}$. Ventilação boca-a-boca e boca-máscara estão proscritas ${ }^{12}$.

Não há dados suficientes para apoiar a ressuscitação cardiopulmonar extracorpórea (RCP-E) para pacientes com COVID-193.

\section{Ajustes do ventilador mecânico: circuito fechado durante RCP}

Diferente dos protocolos de RCP utilizados até então, nos casos de PCR em pacientes com COVID-19sob ventilação mecânica, a conexão ao ventilador em circuito fechado deve ser mantida $a^{3,11,12}$.

Alguns ventiladores mecânicos apresentam a função "RCP/PCR"12, entretanto para aqueles que não dispõem, as principais recomendações para permitir ventilação assíncrona são: ajustar o modo a fim de garantir um volume corrente de $6 \mathrm{~mL} / \mathrm{kg}$ de peso corporal ideal ${ }^{3}$; frequência de $10 / \mathrm{min}^{3}$ a $12 / \mathrm{min}^{11}$; fração inspirada de oxigênio a $100 \%{ }^{11}$; manter trigger desligado (para impedir que o ventilador seja acionado automaticamente com compressões torácicas e possivelmente evite a hiperventilação e a retenção de $a r)^{11}$ ou a menor sensibilidade possível; avaliar a necessidade de manter o nível de pressão expiratória final positiva para equilibrar os volumes pulmonares e o retorno venoso; e ajustar os alarmes para evitar a fadiga.

Manter a segurança dos dispositivos (tubo endotraqueal/traqueostomia) assim como do circuito são essenciais no intuito de prevenir a extubação não planejada e desconexão acidental do circuito o que aumentaria a exposição ao aerossol $^{11}$

Assim que o retorno da circulação espontânea (RCE) for alcançada, as configurações do ventilador deverão ser alteradas conforme às condições clínicas do paciente, com a adoção de estratégias de ventilação protetora ${ }^{3,11}$. 


\section{Causas de PCR}

Durante todo o atendimento na PCR as causas reversíveis deverão ser identificadas e tratadas, antes de se considerar as interrupções das manobras. Nas publicações mais atuais sobre COVID-19 há uma especial consideração para hipóxia, acidemia e trombose coronariana ${ }^{7,12}$.

Em pacientes ventilados mecanicamente, há a recomendação da adoção de estratégias de ventilação protetora, todavia casos de pneumotórax foram observados, devendo ser fortemente considerado em qualquer paciente ventilado com agravamento respiratório súbito ${ }^{1}$.

\section{PCR com o paciente em posição prona}

Para pacientes suspeitos ou confirmados com COVID-19 que estão em decúbito ventral sem uma via aérea avançada, recomenda-se o retorno para decúbito dorsal para realização da RCP. Para os que estão na posição prona com vias aéreas avançadas, a colocação na posição supina deve ser evitada, a menos que a manobra seja realizada sem risco de avulsão de dispositivos e desconexão do circuito, o que geraria aerossolização para o ambiente. Em vez disso, as pás adesivas do desfibrilador deverão ser posicionadas ântero-posterior e a RCP com as mãos em posição normal, entretanto, sobre os corpos vertebrais $\mathrm{T} 7 / 10^{8,18}$.

\section{CONSIDERAÇÕES FINAIS}

Frente a pandemia de uma doença altamente contagiosa onde ainda muitas coisas não são totalmente compreendidas, as situações de extrema gravidade, como a parada cardiorrespiratória, tornam-se um enorme desafio para toda a equipe multiprofissional.

Observa-se que as informações disponíveis na literatura sobre o tema ainda se baseiam em consensos de especialistas, relatos de casos e experiências ou estudos unicêntricos com amostras reduzidas, não oferecendo, portanto, altos níveis de evidências. No entanto, aprendendo com experiências anteriores com SARS e compreendendo os fatores epidemiológicos atuais do COVID-19, os profissionais envolvidos na ressuscitação cardiopulmonar estarão muito melhor preparados para se protegerem durante procedimentos geradores de aerossóis.

O bom conhecimento da prevenção e controle de infecções, vigilância em medidas de proteção, a adesão estrita à colocação e retirada de EPI e a preparação para o atendimento de pacientes infectados são de extrema importância. Fica clara a importância de que os profissionais de saúde envolvidos no atendimento aos pacientes suspeitos e/ou confirmados pela contaminação por COVID-19 devem seguir com rigor todo o protocolo estabelecido para o atendimento da PCR para que se minimize o risco de contágio pelo vírus e disseminação do mesmo.

Sugere-se que se fortaleça a cooperação entre equipe assistencial e pesquisadores para o desenvolvimento de registros de dados que possam ajudar no melhor entendimento da natureza dessa doença, em especial da parada cardiorrespiratória, no contexto nacional.

\section{REFERÊNCIAS}

1. Wax RS, Christian MD. Practical recommendations for critical care and anesthesiology teams caring for novel coronavirus (2019nCoV) patients. Can J Anesth [Internet], 2020 [cited 2020 apr 25]; 67: 568-76. DOI: https://doi.org/10.1007/s12630-020-01591-x

2. Organização Mundial da Saúde. Folha informativa - COVID-19 (doença causada pelo novo coronavírus) [Internet]. Organização Pan-Americana da Saúde, 2020 [cited 2020 mai 23]. Available from: https://www.paho.org/bra/index.php?option=com_content\&view=article\&id=6101:covid19\&ltemid=875

3. Edelson DP, Sasson C, Chan PS, Atkins DL, Aziz K, Becker LB, et al. Interim Guidance for Basic and Advanced Life Support in Adults, Children, and Neonates With Suspectedor Confirmed COVID-19: From the Emergency Cardiovascular Care Committee and Get With the Guidelines ${ }^{\circledR}$-Resuscitation Adult and Pediatric Task Forces of the American Heart Association in Collaboration with the American Academy of Pediatrics, American Association for Respiratory Care, American College of Emergency Physicians, The Society of Critical Care Anesthesiologists, and American Society of Anesthesiologists: Supporting Organizations: American Association of Critical Care Nurses and National EMS Physicians [published online ahead of print, $2020 \mathrm{Apr} 9$ ]. Circulation [Internet], 2020 [cited 2020 apr 25]. DOI: https://doi.org/10.1161/circulationaha.120.047463

4. Associação de Medicina Intensiva Brasileira- AMIB. Orientações sobre o manuseio do paciente com pneumonia e insuficiência respiratória devido a infecção pelo Coronavírus (SARS-CoV-2), [Internet], 2020 [cited 2020 apr 25]. Available from: https://www.amib.org.br/fileadmin/user_upload/amib/2020/marco/20/1_Orientacoes_sobre_o_manuseio_do_paciente_com _pneumonia_e_insuficiencia_respiratoria_devido_a_infeccao_pelo_Coronavirus_ai.pdf

5. Xie J, Tong Z, Guan X, Du B, Qiu H, Slutsky AS. Critical care crisis and some recommendations during the COVID-19 epidemic in China. Intensive Care Med [Internet], 2020[cited 2020 apr 25]; 46:837-40. DOI: https://doi.org/10.1007/s00134-020-05979-7

6. American Heart Association. Destaques das Diretrizes da AHA 2015 - atualização das diretrizes para RCP e ACE. Emerg Cardiovasc Care Programs [Internet], 2015[cited 2020 apr 25]. Available from: https://eccguidelines.heart.org/wpcontent/uploads/2015/10/2015-AHA-Guidelines-Highlights-Portuguese.pdf

7. Resuscitation Council UK. RCUK Statement on PHE PPE Guidance. Resusc Counc UK [Internet], 2020 [cited 2020 apr 28 ]. Available from: https://www.resus.org.uk/media/statements/resuscitation-council-uk-statements-on-covid-19-coronavirus-cpr- 
and-resuscitation/statement-on-phe-ppe-guidance/

8. Resuscitation Council UK. Resuscitation Council UK Statement on COVID-19 in relation to CPR and resuscitation in acute hospital settings. Resusc Counc UK [Internet], 2020 [cited 2020 apr 06]. Available from:

https://www.resus.org.uk/media/statements/resuscitation-council-uk-statements-on-covid-19-coronavirus-cpr-andresuscitation/covid-healthcare/

9. American College of Surgions Committee on Trauma. Advanced Trauma Life Suport- ATLS [Internet], 2018 [cited 2020 apr 06]. Available from: https://viaaerearcp.files.wordpress.com/2018/02/atls-2018.pdf

10. PHTLS Committee of the National Association of Emergency Medical Technicians. PHTLS Atendimento Pré-Hospitalar ao Traumatizado.8ed. Jones \& Bartlett Publishers; 2016.

11. Guimarães HP, Timerman S, Correa T, Dos R, Rodrigues R, Freitas AP, et al. Recomendações para Ressuscitação Cardiopulmonar (RCP) de pacientes com diagnóstico ou suspeita de COVID-19 Recomendações para Ressuscitação Cardiopulmonar (RCP) de pacientes com diagnóstico ou suspeita de COVID-19 [Internet], 2020 [cited 2020 apr 25]. Available from: http://abramede.com.br/wp-content/uploads/2020/03/RCP-ABRAMEDE-SBC-AMIB-7-230320.pdf

12. Associação de Medicina Intensiva Brasileira- AMIB. Recomendações da Associação de Medicina Intensiva Brasileira para a abordagem do COVID-19 em medicina intensiva [Internet]; 2020. [cited 2020 apr 25]. Available from: https://www.amib.org.br/fileadmin/user_upload/amib/2020/abril/04/Recomendacoes_AMIB04042020_10h19.pdf

13. Agência Nacional de Vigilância Sanitária. Orientações para serviços de Saúde: medidas de prevenção e controle que devem ser adotadas durante a assistência aos casos suspeitos ou confirmados de infecção pelo novo coronavírus (SARS-CoV-2) [Internet]; 2020 [cited 2020 apr 25]. Available from: http://portal.anvisa.gov.br/documents/33852/271858/Nota+T\%C3\%A9cnica+n+042020+GVIMS-GGTES-ANVISA/ab598660-3de4-4f14-8e6f-b9341c196b28

14. Shao F, Xu S, Ma X, Xu Z, Lyu J, Ng M, et al. In-hospital cardiac arrest outcomes among patients with COVID-19 pneumonia in Wuhan, China. Resuscitation [Internet]. 2020 [cited 2020 apr 25]; 151(1277):18-23. DOI: https://doi.org/10.1016/j.resuscitation.2020.04.005

15. American Heart Association. Oxygenation and Ventilation of COVID-19 Patients. Module 2: Airway Management [Internet]. 2020 [cited 2020 apr 25]. Available from: https://cpr.heart.org/en/resources/coronavirus-covid19-resources-for-cprtraining/oxygenation-and-ventilation-of-covid-19-patients

16. Fritz Z, Perkins GD. Cardiopulmonary resuscitation after hospital admission with covid-19. BMJ [Internet], 2020 [cited 2020 apr 25]; 369:m1387. DOI: http://dx.doi.org/doi:10.1136/bmj.m1387

17. American Heart Association. Oxygenation and Ventilation of COVID-19 Patients Module 1: Non-invasive Support Overview [Internet]. 2020 [cited 2020 apr 25]. Available from: https://cpr.heart.org/en/resources/coronavirus-covid19-resources-for-cprtraining/oxygenation-and-ventilation-of-covid-19-patients

18. Cheung JC-H, Ho LT, Cheng JV, Cham EYK, Lam KN. Staff safety during emergency airway management for COVID-19 in Hong Kong. Lancet Respir Med [Internet]. 2020 [cited 2020 apr 25]; 8(4):e19. DOI: https://doi.org/10.1016/S2213-2600(20)30084-9 